\title{
O Projeto Arqueológico e a Possibilidade de Ver e Dizer na Midia
}

\author{
The Archaeological Project and the Possibility \\ to SeE and Tell in Mass Media
}

Josiane dos Santos LIMA*

Kátia Menezes de SOUSA**

As formas originais de pensamento se introduzem por si mesmas: sua história é a única forma de exegese que elas suportam, e seu destino a única forma de crítica.

Michel Foucault

Resumo: O objetivo deste estudo é problematizar alguns enunciados veiculados pela mídia, tomando como hipótese a ideia de que o dizível e o visível construídos pelo trabalho interpretativo da rede midiática tornam possível a compreensão do nosso presente. Para a construção de um dispositivo de análise que permita a problematização da atualidade, o referencial teórico é constituído, principalmente, pelos fundamentos do projeto arqueológico de Michel Foucault. Os enunciados que circulam na mídia são atravessados por discursos de outras instâncias enunciativas, que, reconfigurados, povoam os dizeres que circulam nos lugares mais diversos, incluindo os próprios modos de existência dos sujeitos. O discurso competente faz funcionar um jogo de verdade ou, mais precisamente, se encaixa no que Foucault analisou como parte de um sistema de exclusão, a vontade de verdade. Tal vontade é sustentada por um suporte institucional, que assegura o acesso, os comentários, os esquecimentos e a redistribuição dos vários discursos. Assim, acabamos por incluir novas medidas em nosso

* Doutoranda em Linguística na Universidade Federal de Goiás. Mestrado em Linguística na UFG (2009). Contato: josianereal@hotmail.com.

** Doutorado em Linguística e Língua Portuguesa na Universidade Estadual PaulistaAraraquara (2002). Mestrado em Linguística na Universidade Federal de Goiás (1995). Professora da Faculdade de Letras/UFG. Contato:km-sousa@uol.com.br. 
cotidiano e excluímos hábitos e modos de fazer que nos acompanham por longo tempo. Essa dinâmica faz funcionar uma rede importante de agenciamentos e dispositivos. Isso demonstra um trabalho sutil e eficaz da relação poder/saber.

Palavras-chave: Enunciados. Saber. Mídia.

Abstract: The aim of this study consists to discuss some discursive statements distributed by advertising medium. Our hypothesis contemplates the idea that the told and visible things are constructed by the understanding work of media net that makes possible the sense of our present. In order to construct an analyses device to discuss the present, the theoretical support is formed by the basis of Michel Foucault's archaeological description. The statements distributed in media are crossed by discourses of others discursive spaces, that, being modified, they occupy the words that circulate in the most different places, including the way of subject living. The appropriate discourse sets going a truth game and it becomes part of an exclusion system, the will to truth, as it was analyzed by Foucault. This will to truth is supported by an institutional basis, which ensures the appropriation, comments, oblivions and distribution of many discourses. In this way, we include new attitudes in our daily life and we exclude habits and manners that go along with us. This mechanism makes to work an important net of confiscations and devices. It demonstrates a subtle and effective work of the power/knowledge relation. Key-words: Discursive statements. Knowledge. Media.

\section{Introdução}

Este trabalho intenta problematizar alguns enunciados veiculados pela mídia, sob a hipótese de que o dizível e o visível construídos pelo trabalho interpretativo da rede midiática tornam possível a compreensão do nosso presente. Para a construção de um dispositivo de análise que permita a problematização da atualidade, o referencial teórico é constituído, principalmente, pelos fundamentos do projeto arqueológico de Michel Foucault. Nesse sentido, os comentários realizados aqui tenderão, então, a enxergar as construções discursivas, não como simples vontade de um indivíduo, mas como um trabalho de coerência tecido na história. 
Assim, veremos que por "meio da mídia" - isso já uma redundância - a seleção e distribuição da informação constroem um espaço discursivo possuidor de seus mecanismos estratégicos e de uma linguagem facilmente reconhecível. Os enunciados que materializam a informação podem, pela instância enunciativa, atravessar outras séries de enunciados já efetivados e surgir na constituição dos dizeres que circulam nos outdoors, nas revistas, nas propagandas da TV, em campanhas governamentais e nos lugares mais diversos, incluindo os próprios modos de existência dos sujeitos.

\section{A Construção Arqueológica de Foucault}

A trajetória intelectual de Foucault certamente nunca se manteve ao largo de debates que miraram a nossa atualidade. Falar desse filósofo é trazer à baila questões que atravessam a própria constituição de um sujeito do presente. As questões por ele trabalhadas trazem consigo todas as lutas e embates, nós e rupturas de sua história sempre a se refazer. Alguns dirão, dentre eles Deleuze (1992), que Foucault renova a questão da morte do homem proposta por Nietzsche, mostrando que as relações de força atuam sobre uma linha de vida e de morte que não para de se dobrar e se desdobrar, traçando o próprio limite do pensamento.

Segundo Deleuze (1992), a própria condição do pensamento entra na mira de Foucault, tendo em vista que pensar é, antes de tudo, ver e falar, mas com uma condição significativa. Ou seja, o olho não deve permanecer nas coisas, ele deve se elevar até as visibilidades e, por sua vez, a linguagem não está limitada às palavras ou mesmo às frases, ela deve se elevar até os enunciados. Para Deleuze isso é a própria construção do pensamento como arquivo. A história, na perspectiva foucaultiana, nos envolve e também nos limita; não apenas diz o que somos, mas também aquilo de que estamos em via de diferir; não situa nossa identidade, mas sim a dissipa em razão do outro que somos (DELEUZE, 1992).

Em um de seus textos, Deleuze (1992, p. 113) disse que "há pessoas que não se sentem inteligentes senão quando descobrem 'contradições' num grande pensador". Certamente podemos afirmar que Michel Foucault foi um destes grandes pensadores, ora mal compreendido, ora duramente criticado. Este novo "arquivista" se propôs a se ocupar apenas de enunciados. Se assim podemos dizer, estava aí instaurado um nó. O que compreenderia tal tarefa? O que seria o próprio enunciado? 
As respostas a tais questões permeiam o projeto foucaultiano, basta ver todo o trabalho analítico realizado em As palavras e as coisas: uma arqueologia das ciências humanas (produção da década de 1960). Aquele foi um momento em que Foucault fez funcionar plenamente a rede de enunciados que foram possíveis na constituição histórica dos saberes, os quais, por sua vez, resultaram na invenção do homem. Tal homem, aliás, fora visto como uma construção histórica ligada à produção de saberes, contrariamente ao que era proposto pelas teorias transcendentais do sujeito. E, assim, Foucault (2002, p. 536) diz que

... o homem não é o mais velho problema nem o mais constante que se tenha colocado ao saber humano. Tomando uma cronologia relativamente curta e recorte geográfico restrito - a cultura européia desde o século XVI - pode-se estar seguro de que o homem é aí uma invenção recente. Não foi em torno dele e de seus segredos que, por muito tempo, obscuramente, o saber rondou. De fato, dentre todas as mutações que afetaram o saber das coisas e de sua ordem, o saber das identidades, das diferenças, dos caracteres, das equivalências, das palavras - em suma, em meio a todos os episódios dessa profunda história do mesmo - somente um, aquele que começou há um século e meio e que talvez esteja em via de se encerrar, deixou aparecer a figura do homem [...]. O homem é uma invenção cuja recente data a arqueologia de nosso pensamento mostra facilmente. E talvez o fim próximo.

O projeto de Foucault foi apenas o de compreender "as condições que permitem que ciências e filosofias, objetos e sujeitos, coisas e palavras sejam dispostos numa ordem e segundo regras específicas num momento histórico" (CANDIOTO, 2010, p. 28). Contudo, isso não o fez escapar das mais severas críticas. Alguns acusaram Foucault de ter esquecido a história e de ter criado uma situação contrária aos direitos do homem. Eribon (1996, p. 47), ao comentar as críticas sofridas pelo filósofo francês, diz que a obra de Foucault foi "acusada de levar ao nazismo: abertamente por James Miller, de modo mais sutil por Ferry e Renaut". Até mesmo Sartre, grande filósofo, lido e seguido pelos estudantes franceses na década de 1960, lançou contra Foucault palavras duras, dizendo que ele era "a última barragem que a burguesia ainda pode erguer contra Marx" (apud ERIBON, 1996, p. 51). 
Todavia, não se trata disso. Foucault, como outros em sua época, olhou para a história de um modo diferente, evitando as grandes formalizações, rejeitando tomar sem critérios noções como as de tradição, influência, consciência, evolução, desenvolvimento e mentalidade, porque, conforme sua explicação,

... elas não têm certamente uma estrutura conceitual muito rigorosa, mas sua função é muito precisa. Tal como a noção de tradição, que permite simultaneamente situar qualquer novidade a partir de um sistema de coordenadas permanentes e dar um status a um conjunto de fenômenos constantes. Tal como a noção de influência, que dá um suporte - mais mágico do que substancial - aos fatos de transmissão e comunicação. Tal como a noção de desenvolvimento, que permite descrever uma sucessão de acontecimentos como a manifestação de um só e mesmo principio organizador. Tal como a noção, simétrica e oposta, de teleologia ou de evolução para um estágio normativo. Tais como as noções de mentalidade ou de espírito de uma época, que permitem estabelecer entre fenômenos simultâneos ou sucessivos uma comunidade de sentidos, ligações simbólicas, um jogo de semelhanças e de espelhos. (FOUCAULT, 2004a, p. 87-88).

Michel Foucault fez seu trabalho não pensando apenas os longos períodos. Ele colocou em primeiro plano a questão das rupturas no lugar das continuidades, não enxergando somente causalidades e, sim, um sistema de dispersão. Com propostas não muito bem recebidas, tanto por existencialistas como por marxistas, Michel Foucault construiu uma forma de pesquisa que denominou como arqueológica. Tal proposta passa, então, a considerar outras noções como as de enunciado, o saber, função enunciativa, discurso, ruptura e dispersão.

Contudo, Machado (2006) afirma que poucos sabem que a denominação arqueologia do saber, método ${ }^{1}$ de análise proposto por Foucault,

1 Tomamos a palavras método por nos faltar termo melhor e maior espaço para discutirmos a questão. Contudo, não se deve pensar que se trata de um simples método, o qual depende apenas a pura aplicação a distintos objetos de pesquisa. Conforme Machado (2006), se podemos considerar a arqueologia um método, devemos lembrar que se trata de compreendê-lo em uma variação constante dos seus princípios, pela redefinição de seus objetivos e também pela mudança no sistema de argumentação. 
é antes um ponto de chegada, não propriamente um ponto de partida, pois se trata de um resultado de processo histórico, o qual também fez parte de uma rede de relações, sobretudo, se situou em relação à epistemologia. Assim, segundo Machado (2006), para que o analista consiga dar conta de um determinado discurso, por exemplo, é indispensável tomá-lo tanto interna como externamente.

Para Machado (2006), a história da arqueologia de Foucault pode ser compreendida na medida em que se considera que todas as suas análises estão voltadas para o homem, ou seja, constituem uma grande pesquisa sobre a formação histórica das ciências do homem na modernidade. Contudo, pelo distanciamento que toma das teses epistemológicas, as pesquisas desenvolvidas por Michel Foucault tornam possível um novo tipo de história. Por tal razão, o próprio livro Arqueologia do saber é também visto como um momento de explicitação teórica e metodológica em relação a todo trabalho até então realizado. Em tal ocasião, Foucault trava um grande diálogo não apenas com seus leitores, mas também consigo mesmo, em relação às suas posições teóricas e políticas (GREGOLIN, 2004).

Dessa maneira, é possível compreender que fazem parte de tal trajetória arqueológica obras como História da loucura, a qual está historicamente centrada no período Clássico, e monta toda sua argumentação de modo a esclarecer a situação da loucura na modernidade. Tal obra não aponta simplesmente para a história do nascimento da psiquiatria, ela diz respeito às próprias condições históricas de possibilidade dos discursos e também das práticas que concernem ao louco como doente mental.

Entra ainda para o rol de obras arqueológicas Nascimento da clínica, cujo objeto é a própria doença e o nascimento da medicina moderna. A posição arqueológica mostra que o que está em jogo não é uma situação de desenvolvimento e evolução da medicina. Ocorre que não foi a modemidade que ensinou a ver e a dizer. Na realidade, houve uma mutação no próprio modo de ver e dizer o mundo; houve uma transformação na própria relação entre o objeto do qual se fala e também aquele que pode falar, ou seja, há uma mudança que atinge o próprio estatuto do conhecimento. Assim, conforme Machado (2006, p. 88),

... o objeto da medicina moderna é outro não porque ela consegue ser finalmente um conhecimento objetivo, mas porque diz respeito a outra coisa. No nível do objeto, a ruptura que inaugura a medicina 
moderna é o recorte de um novo domínio, a demarcação de um novo espaço [...]. O que se transformou, portanto, foi o modo de existência do discurso médico no sentido de que ele não se refere mais às mesmas coisas, nem utiliza a mesma linguagem.

Questão não muito distinta daquela colocada pela obra Nascimento da clínica pode ser vista, por exemplo, em relação aos estudos da linguagem, abordados por Foucault em As Palavras e as Coisas. Para a criação da gramática comparada do indo-europeu ou mesmo das línguas românicas, não bastou que o gramático constatasse que o grego, o latim e o alemão se pareciam, como no caso de mêter/mater/mutter, respectivamente. Foi necessário atribuir importância à matéria das palavras, ao posicionamento das vogais e consoantes. Foi imprescindível reconhecer que as palavras não se reduziam ao seu sentido, o que seria uma função especular, que colocaria a matéria sonora apenas como um detalhe (VEYNE, 2011).

Assim, também podemos dizer que a especificidade da análise de Foucault ganha alcance sobre o a noção de discurso com o livro As Palavras $e$ as Coisas, o qual tem como projeto norteador analisar os saberes a partir do que o constitui: a epistémê. Para o autor, em cada época há um espaço de ordem o qual constitui os saberes, espaço que é condição de possibilidade do aparecimento de saberes e determina aquilo que pode ser pensado e como deve ser pensado, o que pode ser dito e como ser dito, e claro, quem são os sujeitos os quais devem ocupar o lugar do dizer, da função enunciativa. Assim, epistémê nada mais é do que o aparecimento de uma ordem em determinado momento histórico, e os saberes que nele surgem, manifestos nos discursos, são tomados como verdadeiros devido à sua influência.

Dentro de sua perspectiva, Foucault (2004a, p. 14) afirmou que era preciso que se abandonasse uma série de noções que estão ligadas ao postulado de continuidade, mesmo porque, "a história contínua é o correlato indispensável à função fundadora do sujeito: garantia de que tudo que lhe escapou poderá ser devolvido; a certeza de que o tempo nada dispersará sem reconstituí-lo em uma unidade recomposta", ou seja, exatamente o contrário do que prevê a pesquisa arqueológica.

Dessa forma, percebemos que há uma outra dimensão para a pesquisa histórica posto que não se busca uma história que é linear, diacrônica e causal. Ao contrário, a questão que se faz está em torno do como, ou seja, quais foram as articulações realizadas para que um objeto pudesse ser criado 
e descrito pela ciência (ARAÚJO, 2008). Nesse sentido, Veyne (2011), sobre a pesquisa histórica, ainda afirma que as origens dificilmente são belas, já que os pensamentos não remontam a um sujeito fundador do verdadeiro, ao contrário, se devem a acontecimentos casuais, que tangem o princípio de singularidade da história do pensamento.

$\mathrm{Na}$ arqueologia, os objetos são tomados como apenas efeito de regularidades discursivas, não podendo pré-existir ao próprio saber, pois algo jamais será objeto de um saber se não houver uma rede de relações históricas que o determinem como tal. Conforme Candioto (2010), a Arqueologia do saber mostra que as ciências reconhecidas e legitimadas tomam um posicionamento equivocado ao situarem os saberes não científicos na região do erro ou da ilusão. Para o autor, a pesquisa arqueológica fundamenta a perspectiva de que justamente os saberes formam o solo de constituição de qualquer ciência. Por tal via, torna-se visível que o saber não é um privilégio da ciência.

Falar de ciência faz chegar ao debate o cortejo da verdade. Foucault não se furtou ao debate e foi reconhecido por Veyne (2011) por trabalhar a verdade no tempo. Tendo em vista todo o redimensionamento dado à pesquisa histórica, Foucault mostrará em suas empreitadas que, a cada época, os homens estão encerrados em discursos que fazem surgir um campo do verdadeiro, não necessariamente a verdade. Logo,

É verdade que a ideia que temos da sexualidade ou da loucura (ideia de que o 'discurso' inconsciente, implícito, capta com mais exatidão, e cuja singularidade e estranheza que não vemos, ele diz mais precisamente) certamente se reporta, com seu discurso, a uma 'coisa em si', a uma realidade que ela pretende representar. A sexualidade, a loucura, isso existe realmente, não são invenções ideológicas. Por mais que se especule ao infinito, o homem continua a ser um animal sexuado, a fisiologia e o instinto sexual o provam. Tudo o que se pensou sobre o amor ou a loucura ao longo dos séculos assinala a existência e como que o lugar das coisas em si. Contudo, não temos verdade adequada dessas coisas, pois só atingimos uma coisa em si por meio da ideia que dela formamos a cada época (ideia de que o discurso é a formulação ultima, a differentia ultima). Só a atingimos, portanto, como 'fenômeno', pois não podemos separar a coisa em si do 'discurso' por meio do qual ela está cingida em nós. 'Encalhada', 
gostava de dizer Foucault. Nada poderíamos conhecer na ausência dessa espécie de pressupostos: se não tivesse havido discursos, o objeto $\mathrm{X}$ no qual se acreditou ver sucessivamente uma possessão divina, a loucura, a desrazão, a demência etc. não deixaria de existir, mas, em nosso espírito, nada haveria em seu sítio. (VEYNE, 2011, p. 22-23).

Assim, o trabalho arqueológico de Foucault se institui mais do que como um momento de reavaliação de trabalhos já realizados. É a compreensão das relações que os discursos, tomados na instância de acontecimento, mantém com os sujeitos, com uma série de práticas discursivas e não discursivas e constituem as coerências de uma época, as condições de possibilidade, os limites da relação entre o visível e o enunciável. Segundo Deleuze (2005, p. 40), a arqueologia não era uma obra para simples reflexão, nem mesmo a proposta de método geral, "era uma orientação nova, como uma dobra reagindo sobre os outros livros", tendo em vista que ela "propunha a distinção entre duas espécies de formações políticas, as 'discursivas' ou de enunciados e as 'não discursivas' ou de meios".

\section{Uma Leitura Deleuziana: ver e dizer}

Reconhecidamente Gilles Deleuze foi, além de um leitor de Michel Foucault, também um grande admirador ${ }^{2}$, sentimento que fora cuidadosamente expressado na elaboração do livro que leva o nome do filósofo, Foucault (1986). Para Deleuze, a confecção do livro fora, antes de tudo, uma necessidade, pois procurou mostrar, em tal obra, as noções determinadas, o conjunto do pensamento de Foucault, ou seja, a própria mudança de nível operada pelo filósofo, o que o forçou a descobrir o poder sob o saber, o que o levou a pensar os modos de subjetivação. E fazer tal percurso foi, nas palavras de Deleuze, atravessar um conjunto de crises, expor-se a uma cadeia vulcânica (DELEUZE, 1992).

${ }^{2}$ Certa vez, quando questionado sobre a composição do livro Foucault, Deleuze disse que "sentia uma verdadeira necessidade de escrever este livro. Quando morre alguém que se ama e admira, às vezes se tem a necessidade de lhe traçar o perfil. Não para glorificá-lo, menos ainda para defendê-lo; não para a memória, mas para extrair dele essa semelhança última que só pode vir de sua morte, e que nos faz dizer 'é ele'." 
A questão primordial da filosofia de Foucault, conforme Deleuze, seria questionar o que é o pensamento, compreender o que significa pensar. Assim, ele enxerga a existência de três dimensões, três direções possíveis que configuram a problematização foucaultiana do pensamento as quais seriam: arqueologia do saber, genealogia do sujeito (pensando aí os modos de subjetivação) e os estudos sobre o poder. Dessa forma, Deleuze caracteriza Foucault ao mesmo tempo como arquivista, cartógrafo e topologista (MACHADO, 2009). Conforme Deleuze (1992), tanto a arqueologia como a genealogia podem ser vistas como uma espécie de geologia.

A arqueologia não se detém apenas sobre o passado, posto que há uma arqueologia do presente que se ocupa da constituição do arquivo que, para Deleuze (1992, p. 120), se organiza em duas partes: o arquivo é audiovisual. Seria como se o arquivo, de alguma maneira, fosse permeado por uma falha ou uma fissura, a qual colocaria de uma margem a forma do visível e de outra a forma do enunciável. O autor afirma que é necessário "pegar as coisas para extrair delas as visibilidades", pois o que uma época pode ver, está estritamente ligado a um regime de luz. Por outro lado, também seria preciso "rachar as palavras [...] para delas extrair os enunciados", uma vez que o que se torna enunciável em uma dada época obedece a um regime de linguagem. Assim,

... o grande princípio histórico de Foucault é: toda formação histórica diz tudo o que pode dizer, e vê tudo o que pode ver [...], a loucura no século XVII: sob qual luz ela pode ser vista, e em quais enunciados ela pode ser dita? E nós atualmente: o que somos capazes de dizer hoje, o que somos capazes de ver? (DELEUZE, 1992, p. 121).

Embora Deleuze mostre uma interpretação muito interessante acerca do trabalho desenvolvido por Foucault, tomaremos como foco de nossa observação apenas os apontamentos feitos em relação ao projeto arqueológico. Segundo nos diz Machado (2009), Deleuze possui uma leitura original sobre o conceito de saber proposto por Foucault, tendo em vista que ele o concebe constituído por dois estratos.

Veremos que essa visão de duplos empreendida por Deleuze foi bastante produtiva, conseguindo, por vezes, mapear várias das produções teóricas foucaultianas a partir de tal visada. Dessa forma, surgem os pares nessa inteligibilidade deleuziana: ver/falar, visível/dizível, visibilidade/ 
legibilidade, conteúdo/expressão. Tendo em vista a produção de Foucault e os conceitos construídos por ele, o par que mais nos causa estranhamento certamente é o último.

Conforme Machado (2009), em Foucault, Deleuze procura mostrar que o conceito de saber deve ser interpretado como constituído por uma expressão e um conteúdo, sendo que cada uma dessas partes possuiria uma forma e uma substância. Nessa perspectiva, A Arqueologia do saber já traria um esboço dessa teoria das multiplicidades, tendo em vista que a formação discursiva se encaixa nas formas de expressão, ao passo que as práticas não discursivas se ligariam às formas de conteúdo.

De maneira mais concreta, as articulações feitas por Deleuze colocam, por exemplo, a prisão, descrita em Vigiar e Punir, como uma forma de conteúdo e, de outra parte, os prisioneiros assumiram o lugar de substância do conteúdo; o direito penal se constitui como a forma de expressão e a delinquência como substância de expressão. Deleuze (2005, p. 41-42) afirma, por exemplo, que Vigiar e Punir dá um passo inovador em relação à teoria das duas formas, pois mostra que o direito penal "diz respeito ao enunciável em matéria criminal: é um regime de linguagem”. Como tal, ele classifica e traduz todo tipo de infrações, calcula as penas e, por consequência, faz configurar-se toda uma família de enunciados. Já a Prisão, por sua vez, está do lado do que é visível, não se limita a apresentar o crime e o criminoso, "ela própria constitui uma visibilidade", e, trata-se aí de um regime de luz. Contudo, não se deve perder de vista que a visibilidade não é a maneira de ver do sujeito, pois ele mesmo é um lugar de visibilidade, uma função que foi derivada da própria condição de visibilidade, assim como o observador nas prisões.

Para Fonseca (2003), quando Foucault se dispõe a analisar a formação discursiva, há uma negativa quanto ao uso de concepção de um sujeito transcendental como elemento que organizaria todo o regime dos objetos que constituem tal formação. Dessa forma, as múltiplas maneiras de enunciação não reenviam à função unificadora de sujeito, ao contrário, acabam por manifestar sua dispersão.

Dentro desta leitura deleuziana, é possível dizer que tanto o regime de luz como o de linguagem não podem ser resumidos em uma mesma forma e não possuem uma mesma formação (DELEUZE, 2005, p. 42). A prisão pensada como forma de conteúdo faz erigir seus próprios enunciados, suas regras e regulamentos e o direito penal tomado como forma de 
expressão, "enunciados de delinqüência, tem seus conteúdos: nem que fosse apenas um novo tipo de infração, atentado à propriedade mais que agressões às pessoas". Para Deleuze (2005, p. 42), "O que A Arqueologia reconhecia, mas ainda designava apenas negativamente como meios não-discursivos, encontra em Vigiar e Punir sua forma positiva, que obcecava Foucault em todas as suas obras: a forma do visível, em contraste com a forma do enunciável".

Machado (2009) mostra que o autor consegue encontrar a distinção das duas formas em boa parte das obras foucaultianas. Então, para Deleuze, o saber se torna um agenciamento prático, um dispositivo composto também de duas partes, conforme dissemos anteriormente, o qual comporta o que é da ordem do enunciado e das visibilidades. Desse modo,

História da loucura, ao investigar a época clássica, situa o 'asilo’ como lugar de visibilidade da loucura e a medicina como lugar de formulação dos enunciados sobre a desrazão [...]. Nascimento da clínica analisa as distribuições do visível e do enunciável em vários períodos históricos. (MACHADO, 2009, p. 164-165).

Sabemos que Foucault, em A Arqueologia do saber, mostra sua crítica aos métodos de formalização e de interpretação praticados por uma história tradicional. Aponta que tudo é sempre dito e também visto em uma época, contudo esse trabalho não se dá de maneira nem imediata e nem direta.

Assim, para Deleuze (2005), Foucault mostra que o saber de uma dada época só pode ser interpretado na medida em que se consegue alcançar as próprias condições que tornaram os enunciados legíveis e as visibilidades visíveis. O que se pode concluir, conforme Deleuze (2005, p. 68), é “que cada formação histórica vê e faz ver tudo o que pode, em função de suas condições de visibilidade, assim diz tudo o que pode, em função de suas condições de enunciado". E, para resumir, podemos dizer que, para Deleuze, o pensamento, questão vista como fundamental para o autor, dar-se-ia na disjunção entre ver e falar. 


\section{Visível e Dizível na Mídia: uma ideia em torno da responsabilidade ambiental}

Quando Foucault apresenta seu projeto arqueológico e mostra que pretende realizar uma análise dos discursos e rejeitar algumas categorias que sempre garantiram uma noção de continuidade, faz com que o olhar do analista não se perca em definir representação, pensamentos e temas, mas sim que possa encarar os próprios discursos e tomá-los também como práticas regradas (FOUCAULT, 2004a). O autor pretende entender os "acontecimentos discursivos que possibilitaram o estabelecimento e a cristalização de certos objetos em nossa cultura" (GREGOLIN, 2004, p. 88). Foucault (2006, p. 339) defende uma espécie de "acontecimentalização", que é:

Uma ruptura absolutamente evidente, em primeiro lugar. Ali onde se estaria bastante tentado a se referir a uma constante histórica, ou a um traço antropológico imediato, ou ainda a uma evidência se impondo da mesma maneira para todos, trata-se de fazer surgir uma 'singularidade', mostrar que não era 'tão necessário assim'; não era tão evidente que os loucos fossem reconhecidos como doentes mentais [...]. Ruptura das evidências, essas evidências sobre as quais se apoiam nosso saber, nossos consentimentos, nossas práticas.

Dessa maneira, apresentaremos alguns apontamentos que tornam possíveis a compreensão do nosso presente a partir de um trabalho interpretativo viabilizado pela rede midiática. Como já dito anteriormente, nossa escolha teórica é permeada pela perspectiva de Foucault, e os comentários realizados aqui tenderão, então, a enxergar a construções discursivas não como simples vontade de um indivíduo, e sim como um trabalho de coerência tecido na história.

Sem muitos receios e salvaguardadas as devidas proporções, pode-se dizer que vivemos em um mundo quase totalmente cruzado pelas malhas da informação. E aqueles que ainda não possuem acesso a tal rede também não estão fora do jogo, pois estão contemplados pelas estatísticas, estudos, planos e metas para que todos sejam devidamente incluídos, mesmo que seja na forma de dados, em uma sociedade marcada pela suposta difusão da informação, do conhecimento e do saber. 
Nossos dias nos têm mostrado algo de confortável e arriscado na tarefa que o jornalismo tem de transmitir “a verdade”. É confortável porque as informações nos chegam diariamente de modo rápido e acreditamos estar "antenados" com principais acontecimentos regionais ou mundiais. De outra parte, tal comodidade também nos ajuda a saber das informações e, principalmente, a acreditar que são a verdade sobre tudo o que se vê. Entretanto, conforme Bucci (2003, p.9),

... a idéia de que as notícias de jornal 'retratam a realidade' não faz sentido. Não que os jornais mintam, distorçam, manipulem. Não é isso. Admitamos que os grandes veículos da imprensa se esforcem na direção da objetividade e da verdade factual. Admitamos ainda, que eles sejam bem sucedidos nesse esforço. Mesmo assim, a idéia de que eles 'retratam a realidade' não faz sentido. Faria mais sentido dizer que eles consolidam a realidade, ou aquilo a que chamamos, muito precariamente, de realidade.

Basta um breve exame de revistas, telejornais ou mesmo jornais, sejam eletrônicos ou impressos, para sermos bombardeados por palavras (palavra de ordem ${ }^{3}$ diria Deleuze) nos dizendo como devemos ser tanto em relação à saúde, à educação ou à sexualidade, que, aliás, para alguns, é uma questão de saúde! O mais interessante é que tais informações não nos chegam despretensiosamente. Elas surgem munidas de argumentos supostamente válidos e legitimados, fundamentadas em mil pesquisas e trazidas por um porta-voz, o especialista, geralmente um representante da ciência. O discurso competente faz funcionar um jogo de verdade ou, mais precisamente, se encaixa no que Foucault (2004a) analisou como parte de um sistema de exclusão, a vontade de verdade.

Tal vontade é sustentada por um suporte institucional. Ela é

3 "A unidade elementar da linguagem - o enunciado - é a palavra de ordem. Em vez do sentido comum, faculdade que centraliza as informações, é preciso definir uma abominável faculdade que consiste em emitir, receber, e transmitir as palavras de ordem. A linguagem nem se quer é feita para ser acreditada, mas para obedecer e fazer obedecer." (DELEUZE; GUATTARI, 2007, p. 108). 
... ao mesmo tempo reforçada e reconduzida por todo um compacto conjunto de práticas [...]. Mas ela é também reconduzida, mais profundamente sem dúvida, pelo modo como o saber é aplicado em uma sociedade, como é valorizado, distribuído, repartido e de certo modo atribuído. (FOUCAULT, 2004b, p. 17).

Recebemos, comentamos, esquecemos e redistribuímos vários discursos. No balanço de nossa guerra diária da informação, acabamos por incluir novas medidas em nosso dia a dia e excluímos hábitos e modos de fazer que nos acompanharam por longo tempo. A lista dos certos e errados proclamados pela mídia toma uma proporção significativa. Apesar de tal dinâmica nos parecer bastante "normal", não quer dizer que ela não seja, por outro lado, bastante complexa, fazendo funcionar uma rede importante de agenciamentos e dispositivos. Isso demonstra um trabalho sutil e eficaz da relação poder/saber.

E, por outro lado, nos esforçamos para, desde já, não deixar escapar o indicativo de que existe uma confusão entre o que seria o saber e a ciência, como se os dois conceitos fossem intercambiáveis. Diríamos que as duas instâncias articulam ordens um pouco distintas. Seria o caso de pensarmos que o saber é um nível mais elementar do que a ciência. Em outras palavras, para que uma ciência possa existir, é necessário que existam saberes condizentes com critérios de cientificidade, que obedeçam a determinadas delimitações, dentro do que é ou não científico em dada época.

Dessa forma, "o saber não é o canteiro epistemológico que desapareceria na ciência que o realiza” (FOUCAULT, 2004a, p. 206), já que existem saberes não científicos que continuam existindo ou coexistindo ao lado desses saberes "epistemologizados" e talvez nunca venham a ser de tal ordem. Entretanto, isso não significa que sejam um erro ou uma mera ilusão, exemplos de discursos que não estão na ordem do científico, mas que circulam em nossa sociedade, tão livres e tão presos quanto quaisquer outros discursos, como são os saberes literários e religiosos (MACHADO, 2006).

Todavia, sabemos que não há produção de saber que não instaure um espaço de poder e vice-versa. Conforme nos mostra o próprio Foucault (1987, p.27), "temos que admitir que o poder produz saber (e não simplesmente favorecendo-o porque o serve ou aplicando-o porque é útil)". Em outras palavras, poder e saber estão diretamente implicados; não é possível existir relação de poder sem constituição de um saber, nem saber que não suponha e não constitua, ao mesmo tempo, relações de poder. 
O discurso do jornalismo se dá como uma prática organizada que, em última instância, acaba por organizar uma determinada forma de ver o mundo. O seu dizer estabelece regras, ou seja, ao mesmo tempo em que expressam também legitimam as atribuições de sentido que conferem uma leitura possível de nós mesmos e do mundo. Desse modo, segundo Gomes (2003, p. 41), tais regras

... estão automaticamente estabelecendo valores, e os eleitos correlatos a esses valores; estarão determinando aqueles passíveis de ocupar os lugares de poder ao mesmo tempo que hierarquizam, mostrando quais desses lugares se qualificam. Trata-se da estratificação de relações de poder sendo construídas e mantidas, pois o que caracteriza a discursividade é justamente a determinação de tais relações.

A suposta neutralidade proclamada pela mídia jornalística, então, poderá ser posta em questão. A própria noção de uma notícia, por exemplo, pode ser uma articulação bastante complexa. Parece existir uma espécie de encenação, um trabalho que passará, necessariamente, pelo filtro do que se pode chamar de meios de comunicação, os quais, para muitos, reduzem a realidade a uma condição meramente espetacular. Entretanto, devemos nos arriscar a dizer que a realidade, também, já é uma criação, uma encenação. Isso apenas nos mostra que, de um lado a outro, tudo o que se produz e a rede de enunciados que se espalha por toda parte não são jamais um trabalho neutro. $\mathrm{E}$ os meios de comunicação são mais que meios, mas a própria formação da informação.

Assim, veremos que, por "meio da mídia", a seleção e a distribuição da informação se tornam um espaço discursivo possuidor de seus mecanismos, de uma linguagem facilmente reconhecível. Pode, pela instância enunciativa, se cruzar com séries outras de enunciados e surgir na constituição dos dizeres que podem circular nos outdoors, nas revistas, nas propagandas da TV, em campanhas governamentais e nos lugares mais diversos, incluindo os próprios modos de existência dos sujeitos.

Desde a década de 1990, aparece em uma escala crescente a preocupação com o destino do planeta, seus aspectos ambientais, fatores que desencadeiam catástrofes naturais de ordem mundial e, claro, qual é a parcela de culpa do homem em tal situação. No momento, não é de nosso interesse analisar as estratégias usadas pela divulgação científica, mas sim mostrar que é justamente pelo viés da divulgação que a sociedade pode ter 
acesso a toda uma problemática que, até certo período, era de interesse quase que exclusivo de um grupo bem restrito, seja dentro da própria ciência, com os biólogos, oceanógrafos e toda a rede ligada à ecologia, bem como de grupos ainda mais específicos e nem sempre tão bem aceitos pelo corpo social, como é o caso dos "ativistas" ambientais.

Assim, depois dos anos 90, cada vez mais se tornou comum a aparição de tal temática nos mais diversos lugares, indo da simples preocupação com a reciclagem de matérias até à moda mundial e o comportamento "ecologicamente" correto dos sujeitos na sociedade. Dessa maneira, nos dias atuais, parece comum, senão esperado, que, em qualquer lugar, caiba a discussão acerca das causas, das consequências e das medidas a serem tomadas em relação ao aquecimento global.

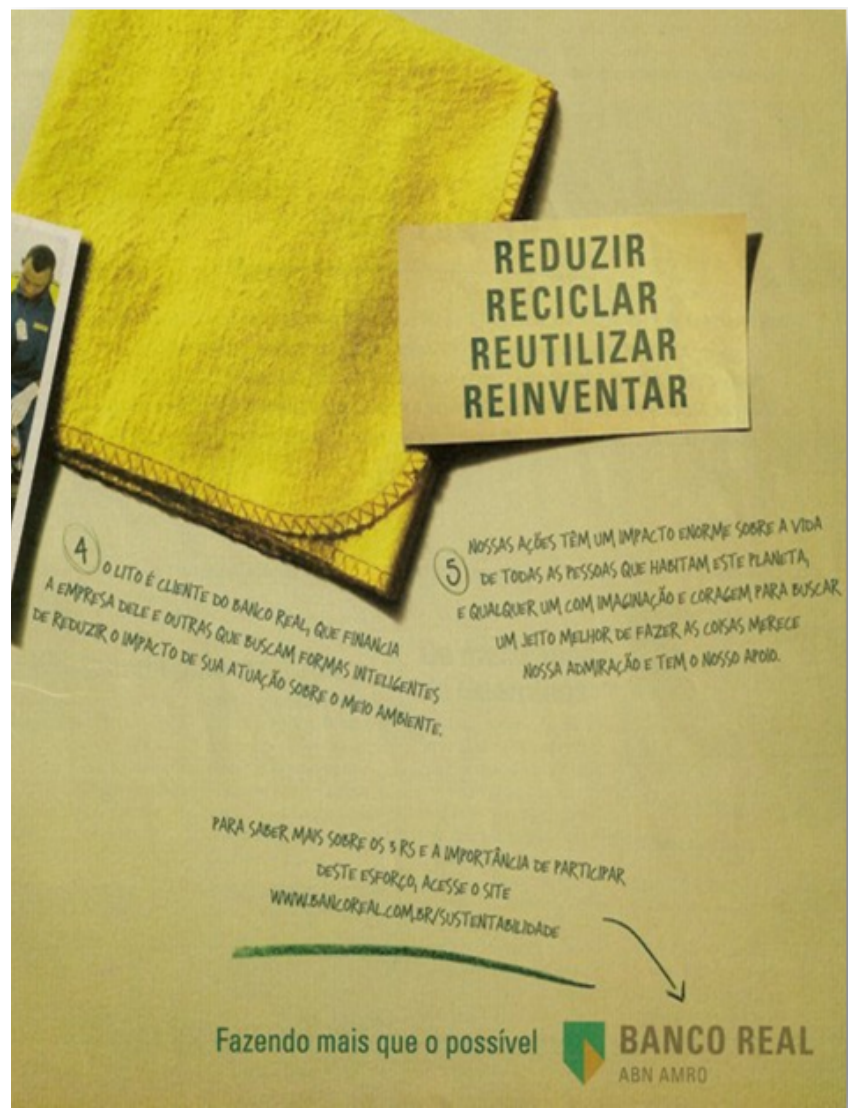

Fonte: Revista Época, n. 463, de 2 de abril de 2007. 
Tomemos como materialização do suposto interesse pelo bem do planeta a propaganda do Banco Real, uma instituição financeira que, grosso modo, poderíamos dizer que em nada tem a ver com questões ambientais ou qualquer coisa que se ligue a tal universo. Entretanto, tal empresa nos apresenta uma mostra do funcionamento discursivo em torno das questões ambientais, propulsionadas pela temática do Aquecimento Global.

O banco, ao falar de suas linhas de crédito e financiamento para pequenos empresários, não lança mão simplesmente da apresentação de vantagens que a empresa poderia oferecer àqueles que buscam um financiamento, mas também procura outro viés. Parte para a ideia do ecologicamente responsável, mostrando que está preocupado com o futuro do planeta, sobretudo, com o uso consciente dos recursos hídricos. Em outros termos, na atualidade, mesmo uma empresa bancária, com interesses econômicos, busca de lucro e exploração de capital, tem que se inserir em uma ordem discursiva que diz que todos são responsáveis pelo futuro seguro do planeta, logo, de seus habitantes. Não basta mais oferecer boas linhas de crédito, razoáveis condições de pagamento, deve-se dar destaque àquilo que supostamente o Banco Real tem como filosofia, algo que regule sua conduta, que dê mostras de uma "ética" aceita e vivenciada.

Se a empresa é ecologicamente consciente, nada mais natural que também dê espaço para os clientes que pensam como ela. Uma engrenagem acaba funcionando de modo muito interessante, pois, ao mesmo tempo em que o discurso da instituição bancária tem que mudar para se adaptar a uma nova ordem discursiva, ela também faz aparecer, nesse seu discurso, mecanismos que selecionam, supostamente, seus clientes em potencial.

Não queremos dizer que, na prática, o banco negaria financiamento a uma empresa de carvão que derrubasse milhões de árvores apenas por conta de um perfil ecologicamente aceitável. Não se trata disso. Pode até ser que negasse realmente, tendo em vista a repercussão disso. Isso não vem ao caso. O que interessa é ver o funcionamento do discurso e a rede discursiva que é instaurada para que uma propaganda como essa do Banco tenha sua condição de existência e, mais que isso, que dê visibilidade a uma norma de conduta, a um modo de existência dos sujeitos.

Entretanto, sabe-se que os discursos não são meras inspirações ou vontades do falante, antes são construções possibilitadas por processos históricos. Assim, o publicitário que propõe uma propaganda nesses moldes apenas toma parte no imenso curso de vozes que, ao longo de quase duas 
décadas, já vem apontado uma preocupação com o futuro do planeta. O público que receberá tal trabalho publicitário também deverá tomar parte na mesma construção de sentido, identificando a instituição Banco Real como ecologicamente responsável e ele, cliente, como alguém conclamado a também fazer a sua parte.

Tanto a instituição bancária, quanto os elaboradores da propaganda, como os clientes do banco estão imersos, em algum momento, em um mesmo ponto do nó discursivo que faz sustentar o discurso de uma postura supostamente correta e, simultaneamente, torna tudo isso passível de ser verdadeiro e aceitável. Dessa forma, devemos também nos questionar como tais valores, tais características de comportamentos são vistas e ditas como positivas, chegando ao patamar de algo a ser seguido e reproduzido.

Não é necessário, nesse caso, que a propaganda cite alguma voz de autoridade ou instituição científica - em alguns casos, isso vai ser necessário -, mas sim que ela apenas faça uso de palavras que se tornaram constantes na identificação da preocupação com as questões ambientais. Assim, aparecem com maior destaque no texto da propaganda as palavras REDUZIR, RECICLAR, REUTILIZAR, já a palavra REINVENTAR aparece como um ponto de junção entre o discurso que circula na sociedade, em relação a tal temática e a postura assumida pelo banco.

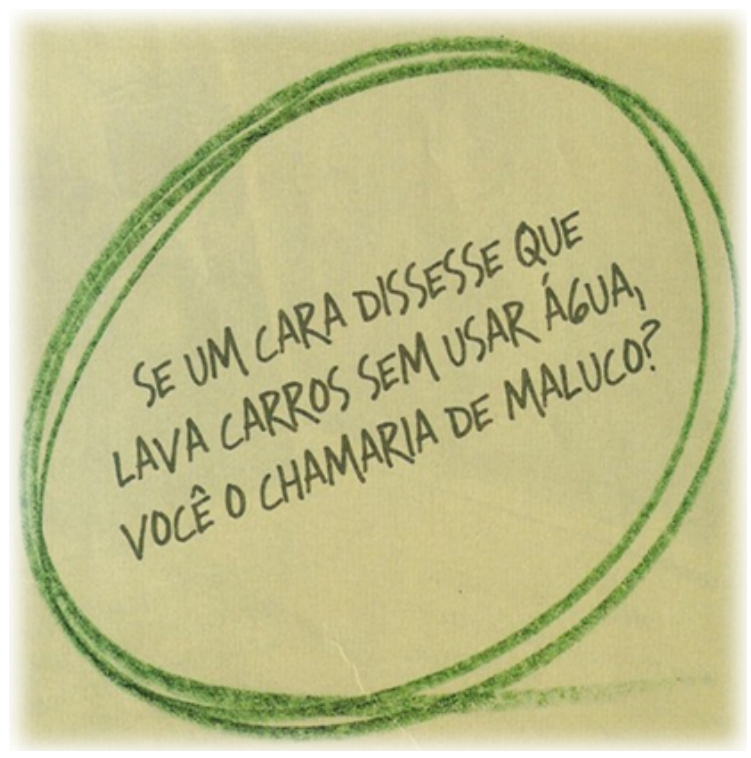


Observemos que o gancho para toda a propaganda é questionar a possibilidade de se "lavar" - processo para o qual se usa principalmente água - um carro sem utilizar água. A ideia, que a princípio poderia parecer loucura, virou investimento e objeto de financiamento no Banco Real, já que é ele que acreditará na "reinvenção" de dados atos com o intuito de preservar o planeta. Desse modo, um discurso que era restrito à comunidade científica, circulando em áreas específicas que se interessavam, sobretudo, por aspectos de correlação entre os seres vivos e seus modos de vida, passou a abarcar uma gama de outros discursos e espaços. Eis um percurso nada homogêneo que tem, em parte, sua origem nos espaços acadêmicos, passa ao conhecimento do grande público, engendra o próprio discurso da sociedade e também, claro, suas possíveis práticas e seus modos de se constituírem como sujeito, materializando o dizível e o visível de nosso tempo ${ }^{4}$.

\section{Considerações Finais}

A partir do breve percurso realizado, podemos perceber que os enunciados veiculados pela mídia operam um mecanismo produtivo em relação à condição de existência de determinadas materialidades discursivas, dando a possibilidade de "ver" e "dizer" em nossa atualidade. Por outro lado, também constatamos que a mídia é um espaço atravessado por uma multiplicidade de discursos, o qual faz acontecer encontros bastante interessantes como, por exemplo, entre ecologia e moda, ou, conforme o material analisado, entre o discurso ambientalista e o bancário/financeiro. Enfim, o que toda essa complexa rede enunciativa nos mostra é que a instituição midiática, na atualidade, é uma peça de destaque na produção e circulação da verdade e, sobretudo, está implicada no trabalho dos modos de condução da vida dos indivíduos. Ela faz parte de um jogo regulador dos modos de existência em nosso presente.

\footnotetext{
${ }^{4} \mathrm{O}$ banco possui uma publicação chamada Cartilha da Ecoeficiência disponível em: $<$ http://sustentabilidade.santander.com.br/oquefazemos/praticasdegestao/ Documents/cartilha_ecoeficiencia.pdf $>$.
} 


\section{Referências}

ARAÚJO, I. L. Foucault e a crítica do sujeito. Curitiba: Ed. da UFPR, 2008.

CANDIOTO, C. Foucault e a crítica da verdade. Belo Horizonte: Autêntica, 2010.

BUCCI, E. O jornalismo ordenador. In: GOMES, M. R. Poder no jornalismo: discorrer, disciplinar, controlar. São Paulo: Hacker; Edusp, 2003. p. 9-13.

DELEUZE, G. Conversações. São Paulo: Ed. 34, 1992.

DELEUZE, G. Foucault. São Paulo: Brasiliense, 2005.

DELEUZE, G.; GUATTARI, F. Mil platôs. Capitalismo e Esquizofrenia. Lisboa: Assírio e Alvim, 2007.

FONSECA, M. A. da. Michel Focault e a constituição do sujeito. São Paulo: EDUC, 2003.

ERIBON, D. Michel Foucault e seus contemporâneos. Rio de Janeiro: JZE, 1996.

FOUCAULT, M. Vigiar e punir. Petrópolis: Vozes, 1987.

FOUCAULT, M. As palavras e as coisas: uma arqueologia das ciências humanas. 8.ed. São Paulo: Martins Fontes, 2002.

FOUCAULT, M. A arqueologia do saber. Rio de Janerio: Forense Universitária, 2004a.

FOUCAULT, M. A ordem do discurso. São Paulo: Edições Loyola, 2004b.

GOMES, M. R. Poder no jornalismo: discorrer, disciplinar, controlar. São Paulo: Hacker; Edusp, 2003.

GREGOLIN, M. do R. Foucault e Pêcheux na construção da análise do discurso: diálogos e duelos. São Carlos: ClaraLuz, 2004.

MACHADO, R. Foucault, a ciência e o saber. Rio de Janeiro: JZE, 2006. 
MACHADO, R. Deleure, a arte e a filosofia. Rio de Janeiro: JZE, 2009.

VEYNE, P. Foucault: seu pensamento, sua pessoa. Rio de Janeiro:

Civilização Brasileira, 2011.

Recebido em março de 2013

Aprovado em agosto de 2013 